\title{
MANUFACTURING ALLOY 706 FORGINGS
}

\author{
J. P. Fesland and P. Petit \\ Aubert \& Duval \\ Les Ancizes, France
}

\begin{abstract}
The demand for very large Alloy 706 components in land based gas turbines has required extensive process development. Successfully manufactured components must be free of deleterious melt related defects and with microstructures necessary to meet mechanical property requirements. This study reviews the process development that was necessary to melt, homogenize and thermomechanically process ingots as large as $1020 \mathrm{~mm}$ in diameter and 20 metric tons in weight into components weighing up to 12 metric tons. Specific examples showing the need to control silicon and homogenization are presented along with a modelling approach used to define the forging parameters.
\end{abstract}

\footnotetext{
Superalloys $718,625,706$ and Various Derivatives Edited by E.A. Loria
}

The Minerals, Metals \& Materials Society, 1994 


\section{INTRODUCTION}

Gas turbines for power generation are setting new challenges for the manufacture of superalloy ingots and forgings. To meet this challenge Aubert \& Duval has developed the manufacturing processes of very large parts made of Alloy 706. The present technology has produced components with diameters up to $2300 \mathrm{~mm}$, thicknesses of $350 \mathrm{~mm}$ and weights up to 12 metric tons. The largest of these parts necessitates the use of starting ingots up to $1020 \mathrm{~mm}$ in diameter and weights up to 20 metric tons.

The major manufacturing milestones of the process for such parts will be examined, and in each particular case, a specific study will be presented.

\section{MELT PROCESSING}

\section{Vacuum Induction Melting}

Successful VIM melting of Alloy 706 requires careful process control to insure consistent results throughout the process. Chemistry control is of utmost importance as is controlling pouring conditions and solidification variables to avoid cracking of electrodes.

The chemistry of the alloy had to be optimized in view of the required mechanical properties, and taking into account the subsequent thermomechanical treatment. As such, the influence of certain alloying elements have been studied. The influence of silicon on the Laves phase and its effect on mechanical characteristics is particularly noteworthy.

\section{Influence of Silicon Content}

A subscale study was carried out to determine optimum silicon levels. A series of $10 \mathrm{Kg}$ VIM experimental heats containing $.04, .12$, and .25 weight percent silicon were prepared. As cast ingot were homogenized and then forged into flats of $65 \mathrm{~mm} \times 1.5 \mathrm{~mm}$.

Figure 1 shows Laves phase precipitation fields as a function of silicon content. Figures 2 and 3 show the results of mechanical testing after solution treating at $980^{\circ} \mathrm{C}$ followed by air cooling and aging. While it appears that the ultimate tensile strength is independent of silicon level, impact strength appears to drop as concentration increases. The SEM examination of the fracture surfaces on the Charpy specimens link directly to low values of toughness (for $\mathrm{Si} \geq$ $.12 \%)$ and the presence of Laves phase.

The study showed the importance of low silicon content in obtaining optimized ductility levels and resulted in the necessary controls. Controling tramp elements like silicon influences the selection of raw materials and affects cost as well as the melting routes.

\section{Secondary Melting}

The requirement for large diameter ingots resulted in the selection of triple melt as a process (VIM +ESR + VAR) necessary to controlling cleanliness and avoiding segregation. 


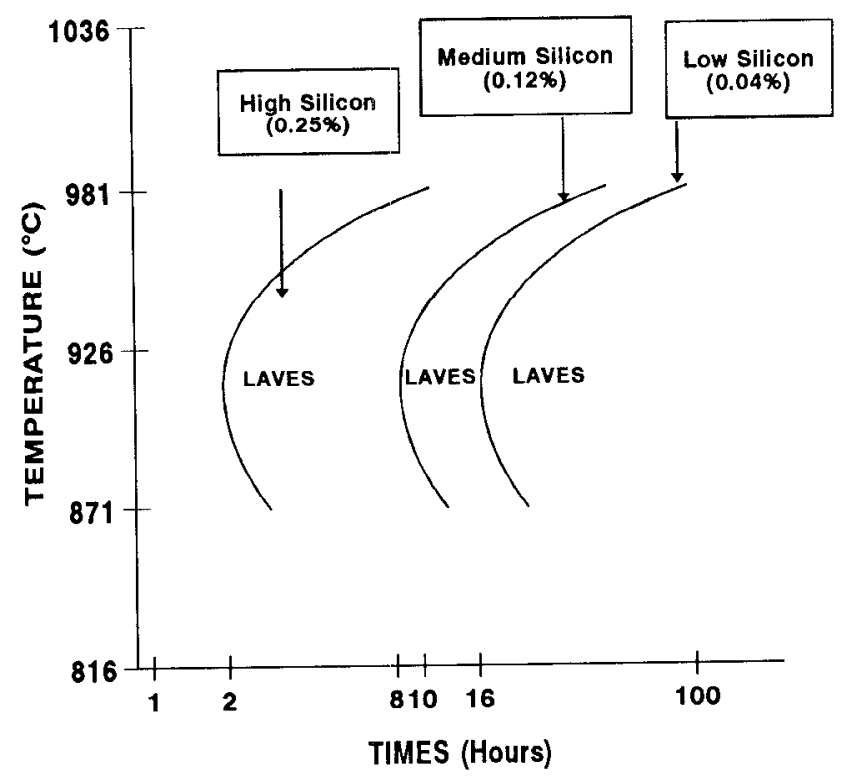

Figure 1: Time-temperature Laves Precipitation Diagram

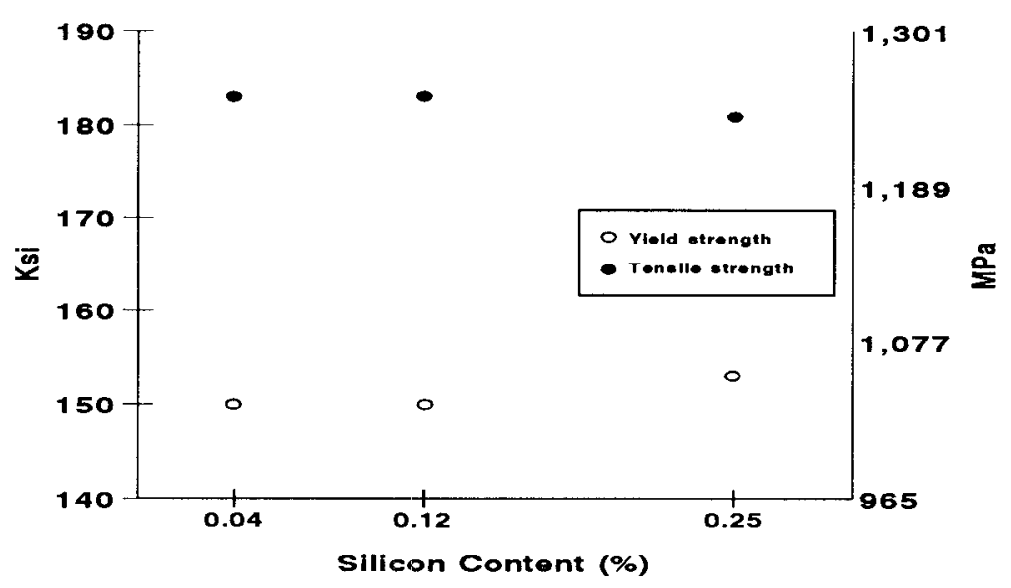

Figure 2: UTS and YS vs. Silicon Content

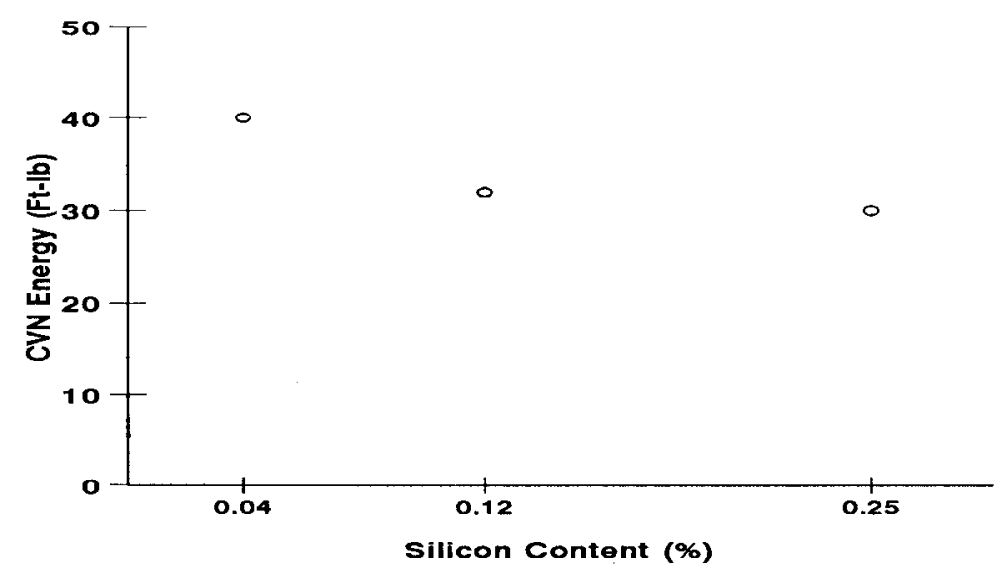

Figure 3: Charpy V-Notch Energy vs. Silicon Content 
Again, process control is critical in producing quality ingots of the sizes needed. Aubert \& Duval's ESR furnace's (13.5-25T) and VAR furnace's (4-30T) melt controls are fully automated with proprietary software developed specifically for these furnaces. Major development work was necessary to fully integrate load cells sensors and electrodes travel. After each remelting operation, a report is automatically printed, with curves necessary to verify the evolution of all the critical parameters. Statistical process control (SPC) is used to continuously set the limits of significant parameters and to improve consistency.

As a validation test for the VAR process, a $1020 \mathrm{~mm}$ diameter ingot was cut-up to document the ingots macrostructure and levels of segregation. The analysis of the structures resulted in measuring a pool depth of approximately $120 \mathrm{~mm}$ in the steady state melt region of the ingot.

It is very important to mention the need to stress relieve electrodes before vacuum remelting. The ingot's susceptibility to cracking in the as-cast state leads to events during remelting. (Events are melt rate irregularities occurring when cracks occur in the melting electrode.) Such events are certainly related to the presence of solidification structure discontinuities inside the electrodes.

Our manufacturing experience (now over 200 ingots) allows us to guarantee that the metal obtained is free from segregations such as freckles or white spots.

\section{BILLET FORGING}

After melting, the ingots are converted into billets with diameters varying from $750 \mathrm{~mm}$ to 1100 $\mathrm{mm}$ according to fixed process procedures. Forging is done on a $4500 \mathrm{~T}$ press with speed control, and a rail integrated manipulator.

In order to obtain good quality billets, the forging procedure has led to the fine tuning of several parameters, such as:

- Heating cycles of ingots: 'This cycle must allow for the slow relieving of internal stresses induced during solidification, thus preventing any risk of cracking.

- Homogenizing treatment, limiting the risk of chemically heterogenous structures.

- Thermomechanical parameters.

Work, carried out in this field to optimize the homogenizing cycle, has been mostly concentrated in understanding the solidification structures of the alloy through the following analytical methods, DTA, SEM and EDS.

The analysis of thermograms (Differential Thermal Analysis, DTA) (Figure 4) has highlighted different solidification sequences.

- Solidification of the austenitic matrix at $1370 / 1390^{\circ} \mathrm{C}$.

- $\quad$ Carbide precipitation of $\mathrm{MC}(\mathrm{Nb}, \mathrm{Ti}) \mathrm{C}$ at $1200 / 1290^{\circ} \mathrm{C}$. The peak is not easily detectible because of the low carbon content $(\mathrm{C}<.02 \mathrm{wt} . \%)$. 
- Precipitation of the Laves phase at $1150^{\circ} \mathrm{C}$ in blocky or eutectic morphology as a function of solidification rate.

- $\quad$ Precipitation of the intermetallic delta phase $\left(\mathrm{Ni}_{3} \mathrm{TiNb}\right.$ in needles) into solid phase around clusters of Laves phase, and for low solidification rates.
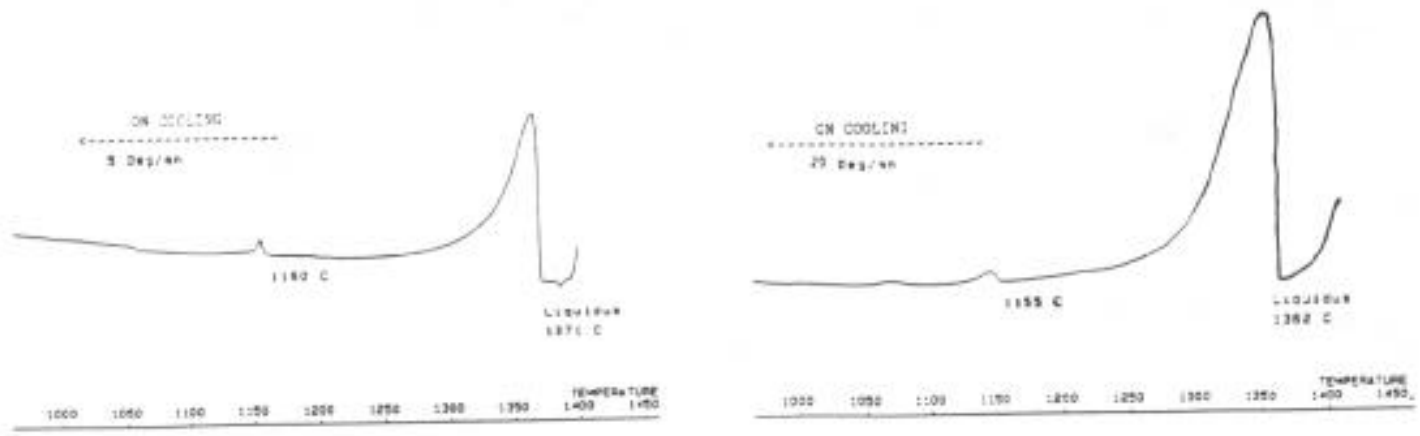

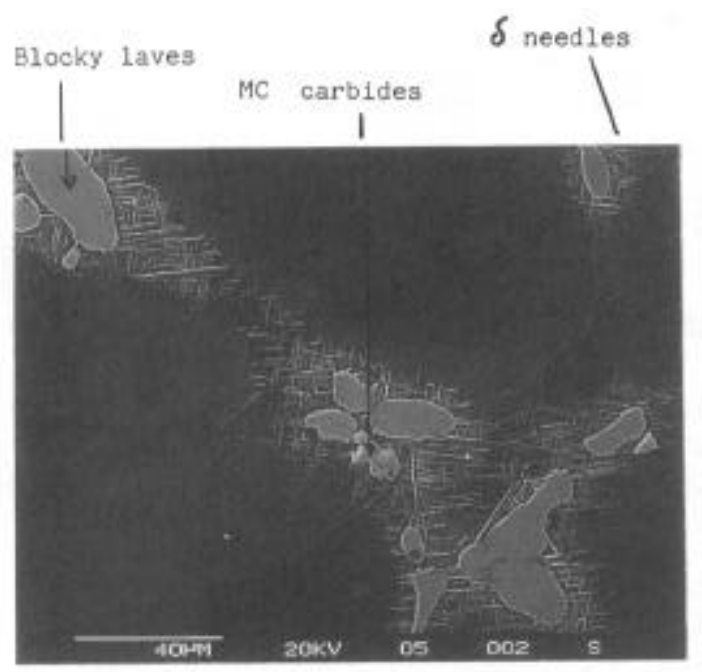

Solldification rate : $5^{\circ} \mathrm{C} / \mathrm{mn}$

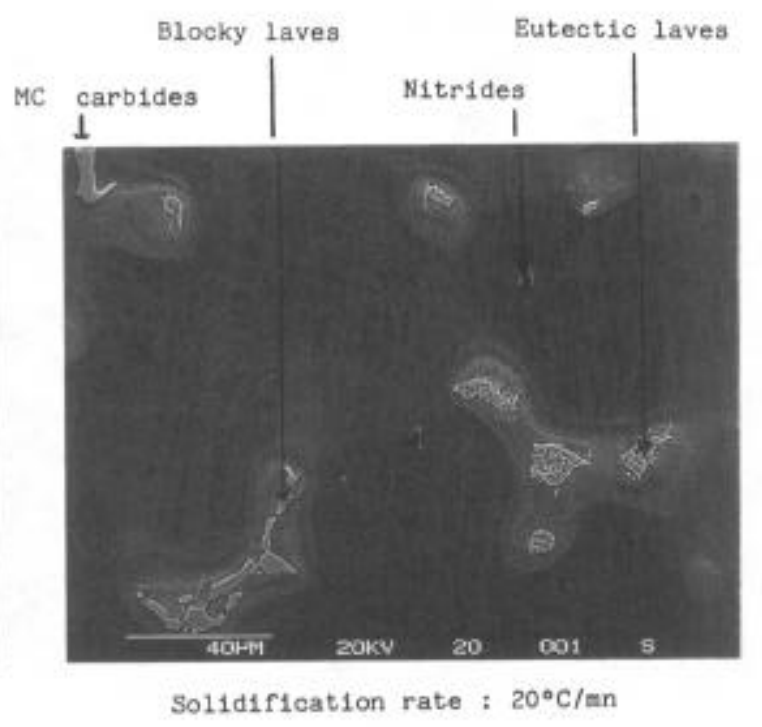

Figure 4: DTA Curves and Associated Microstructures

The analysis of the solidification structure of an as-cast ingot highlights the presence of similar phases. Titanium nitrides are located in the dendritic structures whereas MC carbides, eutectic Laves phases, as well as delta phase needles coexist in interdendritic spaces.

On as-cast samples which were taken from the ingot, the degree of homogenizing was computed through microanalysis for various time/temperature thermal cycles. Figure 5 shows the influence of two different such cycles on the composition variation of columbium. It shows how important the selection of the homogenizing parameters is and how such parameters can be selected for optimal results. 

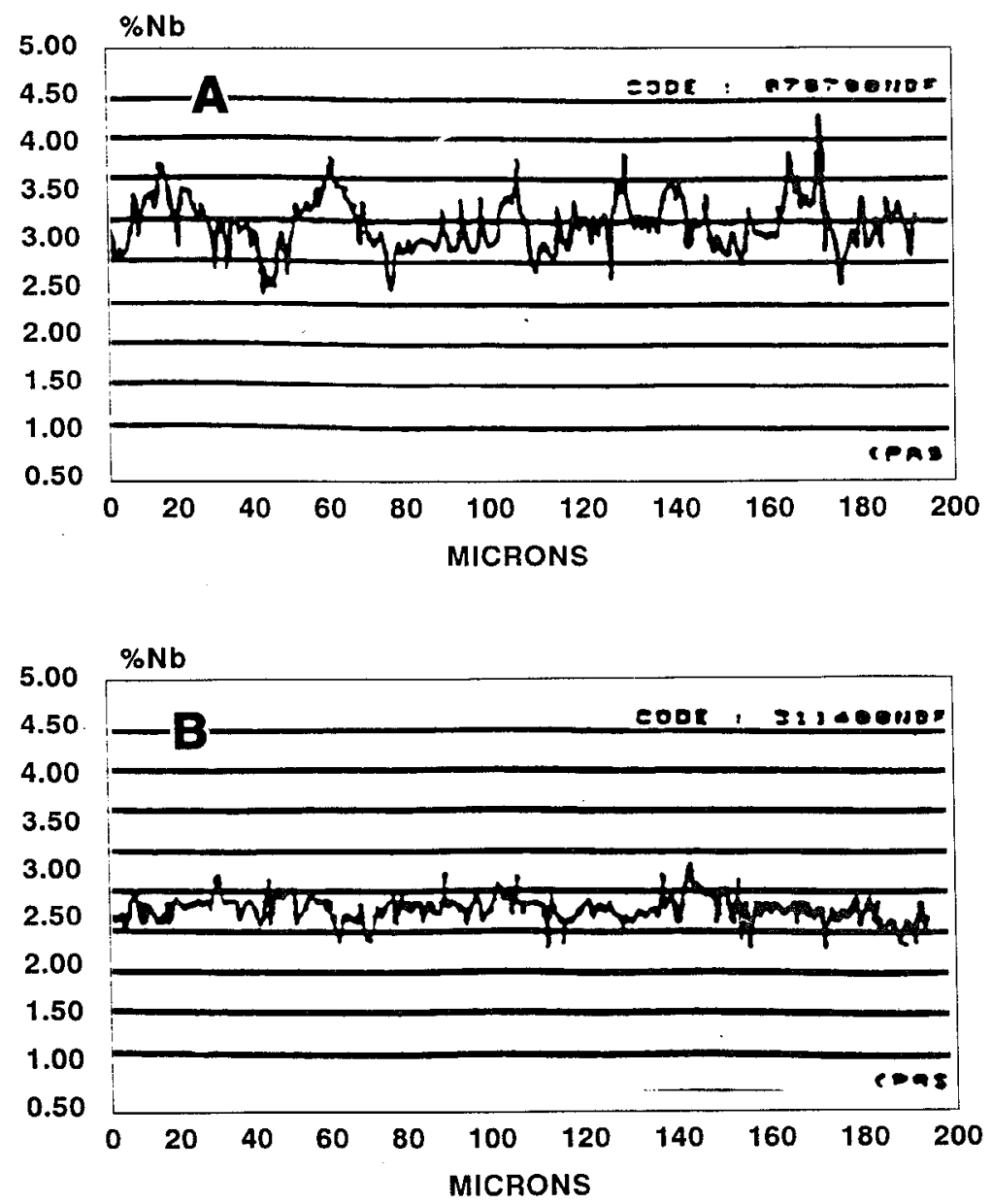

Figure 5: Columbium Variation for Two Different Homogenization Processes (Microprobe Analysis)

After conversion, the billets undergo conventional tests such as ultrasonic testing and macroscopic inspection. The full control of remelting and conversion allows immediate processing of parts right after cropping of both ends, without having to wait for results on macrographs, thus reducing manufacturing cycle times.

\section{MANUFACTURING OF PARTS}

The very size of the parts necessitates the use of a powerful press. The 65,000 metric ton press at Interforge, partly owned by Aubert \& Duval, adequately meets what is needed and allows the optimizing of the temperature/reduction rate pair of parameters. The closed-die forging procedure leads to a controlled structure that is characteristic of a part with good ultrasonic permeability and the required mechanical properties. 
Optimization of the forging procedures is obtained through computer controlled techniques of modelling. Aubert \& Duval has at its disposal a very complete range of modelling tools:

- Forge II, modelling software for the shaping of axisymetrical and/or twodimensional parts (visco-plastic and anisothermal model).

- Ther II, modelling software for purely thermal simulations (temperature-gradients during furnace to press transfers, during heat-treating, during pre-heat cycles).

- A torsion machine, used in determining material behavioral laws. Such laws are indispensable for the modelling of material shaping and the understanding of deformation and recrystallization mechanisms.

Before the manufacturing process procedure could be established, modelling work was carried out. In the first phase, a rheological model of the material was defined through torsion tests. Such tests were made on actual samples cut from the billet. Typical flow curves are shown in Figure 6. The analysis of such curves was carried out on a computer and led to the following equation:

Stress $\sigma=\sigma_{0} \stackrel{\circ}{\Sigma}^{-111} \quad \Sigma^{-11} \exp \underset{T}{\beta}$

Where $\sigma_{0}, \mathrm{~m}, \mathrm{n}$, and $\beta$ are constants

$\stackrel{\circ}{\Sigma}$ is strain rate

$\Sigma$ is strain

$\mathrm{T}$ is temperature

This is valid in the following field:

$$
\begin{aligned}
& 871^{\circ} \mathrm{C}<\mathrm{T}<1093^{\circ} \mathrm{C} \\
& 10^{-3} \mathrm{~s}^{-1}<\stackrel{\circ}{\Sigma}<10^{-1} \mathrm{~s}^{-1} \\
& 0<\Sigma<2
\end{aligned}
$$

Compared to available compression data, the flow stress happens to be smaller in torsion.

After the necessary data acquisition (behavioral law, thermal properties of this alloy, boundary conditions) several forging procedures were modelled. One of them was selected for making an experimental part. The experimental results thus obtained allowed us to validate:

- The model: the part shape, grain flow, and forging pressure gradient were compared. As shown in Figure 7, a good match exists between predicted and actual values, and this confirms the coherence of the parameters introduced in the Forge II software.

- The process procedure inasmuch as the metallurgical properties answers the requirements. 

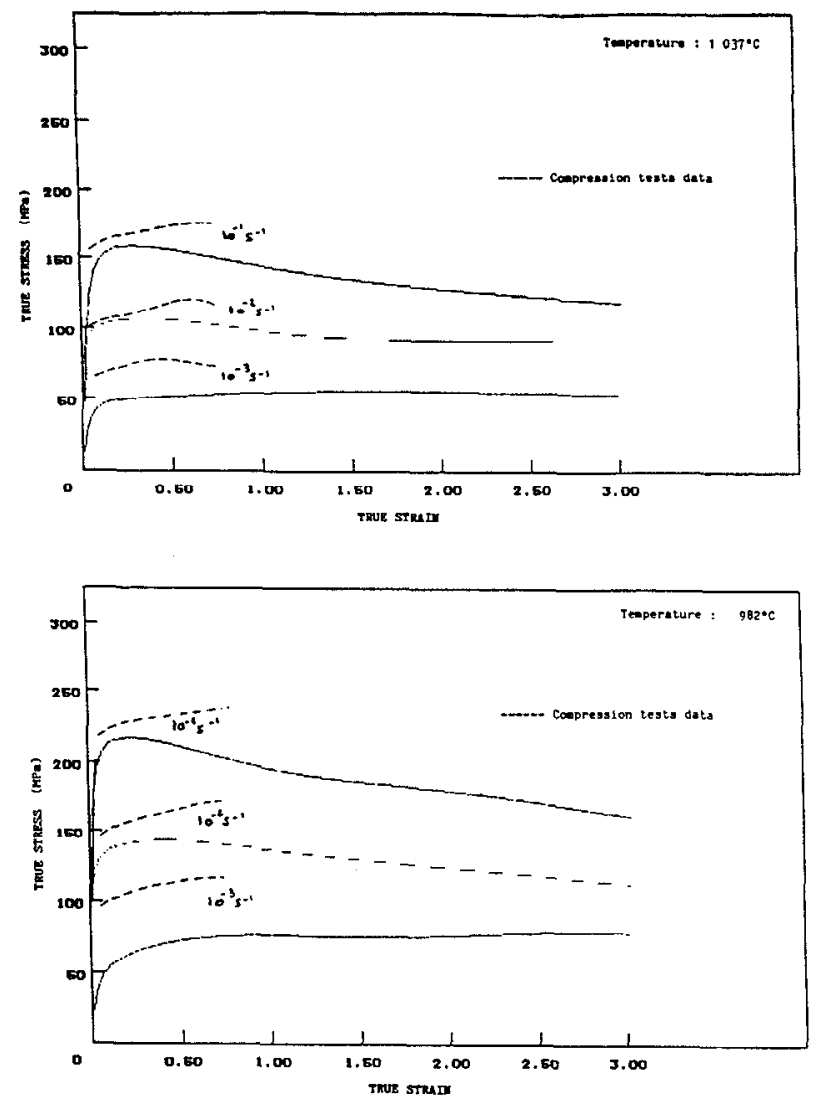

Figure 6: Flow Curves

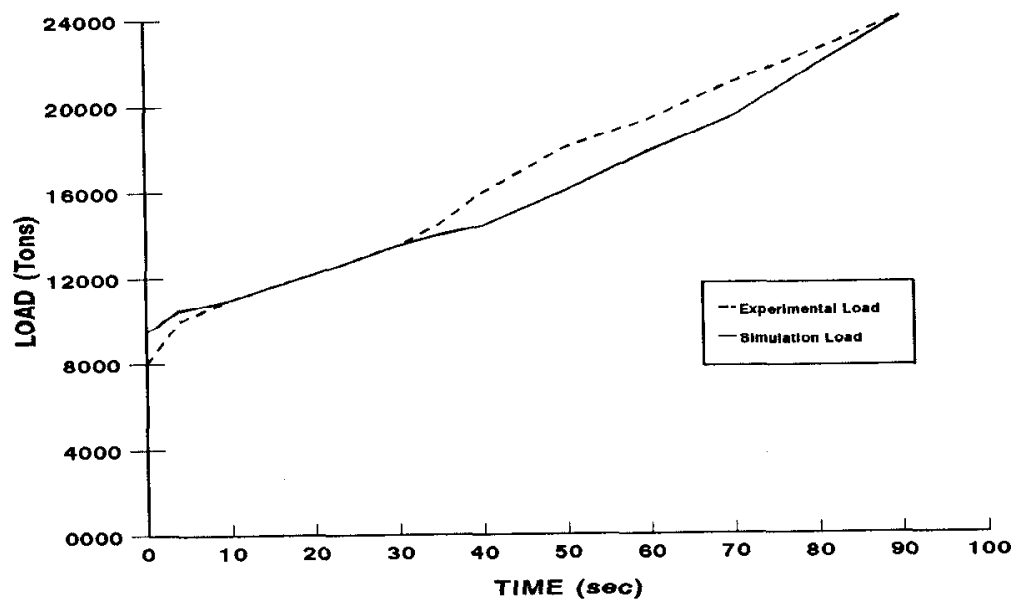

Figure 7: Comparison Between Experimental and Situation Load Curves 
Once this validation phase was over, work proceeded according to two major areas:

- Modelling of the shaping of different types of parts so as to pinpoint the distribution of strains and temperatures.

- Study of recrystallization mechanism for this alloy through the analysis of torsion testing results and comparison of the model forecast (deformation and temperature distribution) with the actual cut-up structure of the as-forged part (Figure 8).

It is clear that the thermal evolution of the part after deformation conditions the recrystallization rate. However, the recrystallized grain size is a function of the two parameters strain/holding time at a temperature higher than that of recrystallization.

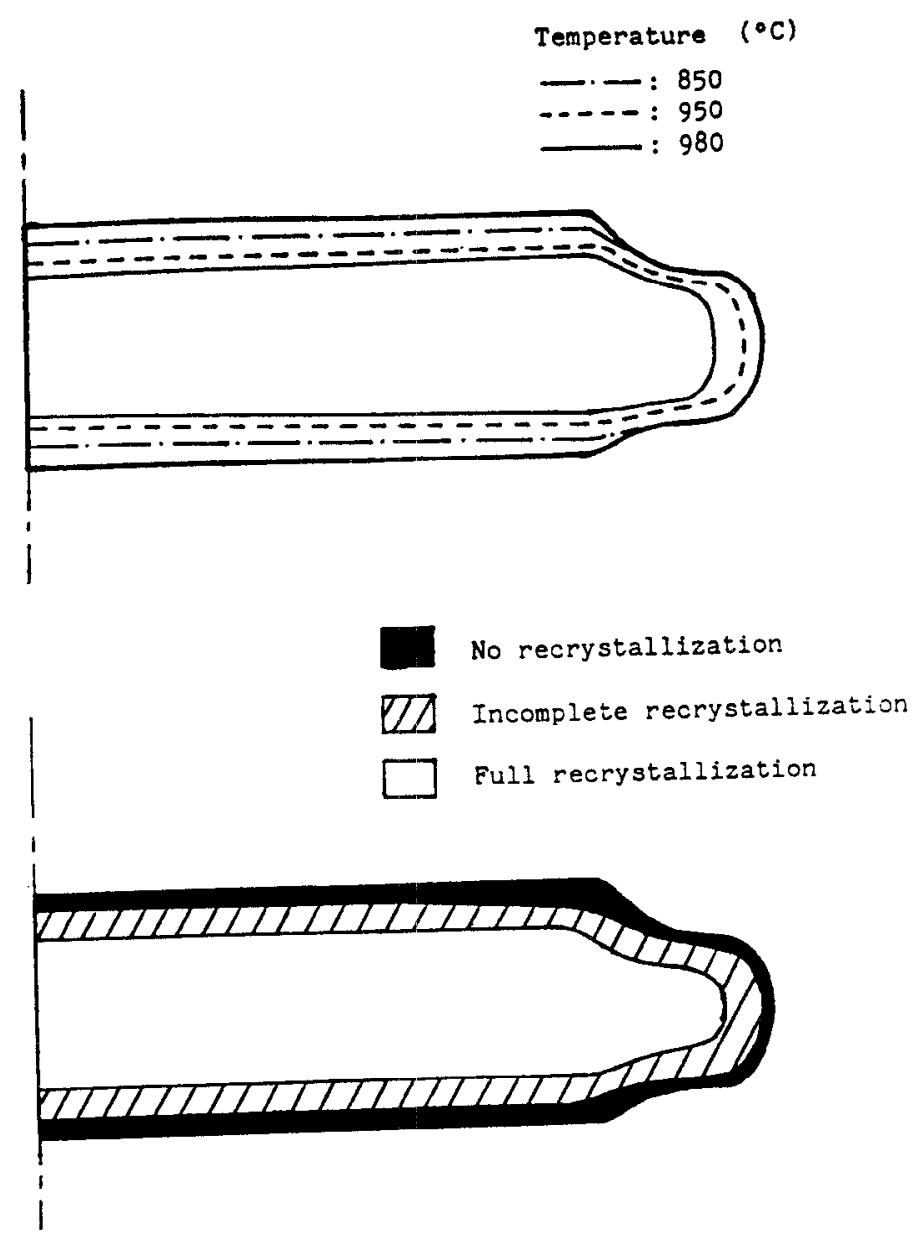

Figure 8: Predicted Temperature and As-Forged Structure

The persistent efforts made both in R\&D and in production have led to changes in process procedures and this has brought about improvements in ultrasonic permeability of the parts. 


\section{IV: FINAL PARTS}

After heat-treatment and machining, parts undergo macrographic etch and ultrasonic testing. All parts tested up until now (over 150) show absolute total conformance to specifications and in particular, a total absence of solidification defects such as freckles and white spots.

Following the most recent process developments, it is now possible to detect the $1.2 \mathrm{~mm}$ FBH within the entire body of the part.

Typical mechanical characteristics, guaranteed within the entire body of the part are shown on Table 1 below.

Table 1: Mechanical Characteristics

\begin{tabular}{|c|c|c|c|c|c|c|}
\hline & $\begin{array}{c}\text { Hts. } \\
\mathrm{MPa}(\mathrm{Ksi})\end{array}$ & $\begin{array}{l}.2 \% \text { YS } \\
\mathrm{MPa}(\mathrm{Ksi})\end{array}$ & $\begin{array}{c}\mathrm{EL} \\
\%\end{array}$ & $\begin{array}{c}\text { RA } \\
\%\end{array}$ & $\begin{array}{l}\text { CVN } \\
\text { ft-lbs. }\end{array}$ & $\begin{array}{c}\text { Grain } \\
\text { Size ASTM }\end{array}$ \\
\hline Tangential & $1206(175)$ & $1000(145)$ & 20 & 35 & 50 & \multirow[b]{2}{*}{$3 / 4$} \\
\hline Axial & $1185(172)$ & $993(144)$ & 14 & 26 & 26 & \\
\hline
\end{tabular}

\section{CONCLUSION}

Even though Aubert \& Duval has been for a long time involved in the manufacturing of superalloy components, the large size Alloy 706 forgings has required a detailed review of each manufacturing stage. Only a few aspects have been covered here.

The industrial experience acquired at this point in time, covering more than 150 forgings, allows Aubert \& Duval to state that the entire process is under control and satisfies the requirements. 